\title{
Growing old with the immune system: a study of immunosenescence in the zebra finch (Taeniopygia guttata)
}

\author{
Elin Noreen $\cdot$ Sophie Bourgeon $\cdot$ Claus Bech
}

Received: 15 October 2010/Revised: 7 January 2011/Accepted: 8 January 2011/Published online: 1 February 2011

(C) The Author(s) 2011. This article is published with open access at Springerlink.com

\begin{abstract}
Immunosenescence has not received much attention in birds and the few existing studies indicate that the occurrence of immunosenescence and/or its extent may differ between species. In addition, not much information is available on the immunosenescence patterns of different immune parameters assessed simultaneously in both sexes within a single species. The present study reports the results on immunosenescence in innate immunity and both cellular and humoral acquired immunity of both sexes in a captive population of zebra finch (Taeniopygia guttata) using three age groups (approximately 0.2, 2.5 and 5.1 years). Both male and female finches showed an inverse U-shaped pattern in cellular immune function with age, quantified by a PHA response. Males showed stronger responses than females at all ages. In contrast, an increase with age in humoral immunity, quantified through total plasma immunoglobulin Y levels, was found in both sexes. However, our measurements of innate immunity measured through the bacteria-killing ability against Escherichia coli gave inconclusive results. Still, we conclude that both cellular and humoral acquired immunity are susceptible to immunosenescence, and that the sexes differ in cellular immunity.
\end{abstract}

Communicated by I.D. Hume.

E. Noreen $(\square) \cdot$ C. Bech

Department of Biology, Norwegian University of Science and

Technology, 7491 Trondheim, Norway

e-mail: elin.noreen@bio.ntnu.no

S. Bourgeon

Norwegian Institute for Nature Research (NINA), Fram Centre, 9296 Troms $\varnothing$, Norway
Keywords Immunosenescence $\cdot \mathrm{PHA} \cdot \mathrm{IgY} \cdot$ Bactericidal competence $\cdot$ Age $\cdot$ Zebra finch

\section{Introduction}

Ageing of an organism is defined as an inevitable physiological senescence in the form of progressive deterioration of body structures and functions (Holmes and Martin 2009). The immune system, which is crucial in terms of protection against parasites and diseases (Goldsby et al. 2003), is no exception to such alterations. Immunosenescence is, therefore, thought to increase the susceptibility to infection and the risk of autoimmune diseases and cancer (Miller 1996; Pawelec et al. 2002), further leading to higher morbidity and mortality rates. Although this is well documented in humans, domesticated animals and laboratory rodents (Blasco 2002; Effros 2003), the knowledge about avian immunosenescence is still limited. However, the use of birds as a model for studying the biology of ageing is increasing (reviewed in Holmes and Ottinger 2003; Monaghan et al. 2008), mainly because of their unexpectedly slow ageing rate and long life spans, despite their small body sizes and high metabolic rates (Holmes and Martin 2009).

Although the immune system shows an enormous complexity, it is generally classified into two main components: innate and acquired immunity (Goldsby et al. 2003). Each of these components is further divided into humoral and cellular immunity, but the interactions between the different systems are immense (Goldsby et al. 2003). In mammals, immunosenescence is revealed by a decline in both cellular ( $\mathrm{T}$ cells) and humoral (B cells) acquired immunity (Miller 1996), with T cell immunity showing the most prominent decline (Pawelec et al. 2002; 
Son et al. 2003). Even though ageing impairs innate cellular function of neutrophils and macrophages (reviewed in Gomez et al. 2008), other innate parameters, such as autoantibodies levels are often preserved with age (Franceschi et al. 2000). In accordance with these findings in mammals, avian studies have reported similar results. For example, tree swallows (Tachycineta bicolor), Leach's storm-petrels (Oceanodroma leucorhoa), ruffs (Philomachus pugnax), quails (Coturnix coturnix japonica) and male zebra finches (Taeniopygia guttata) demonstrated a decrease in cellular acquired immunity with age (Lavoie et al. 2007; Lozano and Lank 2003; Haussmann et al. 2005; Palacios et al. 2007). In addition, female collared flycatchers (Ficedula albicollis) showed an age-related decline in humoral acquired immune function (Cichon et al. 2003). In contrast, no change in humoral acquired or humoral innate immunity was shown with age in common terns (Sterna hirundo; Apanius and Nisbet 2003) or female tree swallows (Palacios et al. 2007). Møller and Haussy (2007) however found that only one of two performed measurements of humoral innate immunity declined with age. The latter results, therefore, indicate that the occurrence of immunosenescence and/or its extent may differ considerably between species.

In addition to these species-specific differences, immunosenescence may differ between the two sexes. Indeed, in the barn swallow (Hirundo rustica), males and females differed in immune response in relation to age with only females showing a significant decline in the primary humoral immune response (Saino et al. 2003). Nevertheless, the secondary immune response declined significantly with age in both sexes. Sex-specific differences in immune function may occur as a result of different life-history strategies. Life-history theory predicts that investment in self-maintenance should decrease with residual reproductive success and expected lifespan (Roff 1992; Stearns 1992). Because reproduction and secondary sexual characters are widely assumed to produce different energy costs between the sexes, sexual differences in investment in immune function, and hence immunosenescence, may arise. In general, reproduction costs are regarded larger for females than for males, while males usually have more costly secondary sexual characters than females (Trivers 1972; Folstad and Karter 1992). The immune system can be regarded as a self-maintenance system, and the resources it requires for optimal function (e.g. energy, protein, nutrients) may, therefore, be traded-off for an increased reproductive effort with age (Cichon 2001; Holmes and Martin 2009). Moreover, it is assumed that the different immune components have distinct and different costs (Matson et al. 2006a) and the relative costs of specific immune functions may change during the lifespan of a bird (Holmes and Martin 2009). Hence, older birds may invest differently in some immune components as compared to younger birds based on their protective value at the time (Norris and Evans 2000; Holmes and Martin 2009) and such a pattern might be explained by the immunoredistribution hypothesis (Braude et al. 1999), i.e. a reallocation of resources from one immune component to another. An energetic shift from one immune component to another like this could further be explained by the avoidance of autoimmune diseases which have been shown to increase with age (Grubeck-Loebenstein and Wick 2002).

Since most studies on avian immunosenescence have assessed a single component of immune function in both sexes, or different immune components in one sex only, there is clearly a need for additional information about the changes with age in innate immunity and both cellular and humoral acquired immunity in both sexes of the same species. The present study, therefore, aimed at detecting potential immunosenescence patterns in a laboratory population consisting of both female and male zebra finches, as this species is expected to be susceptible to immunosenescence (Haussmann et al. 2005). To achieve this, we assessed three components of the immune system: acquired cell-mediated immunity (quantified through the phytohaemagglutinin (PHA) skin test), acquired humoral immunity [quantified via total plasma immunoglobulin Y (IgY) levels] and innate immunity (measured as bactericidal competence) in three different age groups of both sexes. As the population of birds covered the entire lifespan of this species, any occurrence of immunosenescence should be revealed.

\section{Methods}

\section{Study population}

The study was conducted using captive zebra finches, which is a small passerine native to Australasia. The zebra finch is sexually dimorphic with the males exhibiting several plumage characteristics not present in the females, as well as a redder beak (Zann 1996). Our captive colony has been maintained since 2000 and the birds are held in large $\left(10 \mathrm{~m}^{3}\right)$ sex-specific walk-in aviaries. Ambient temperature in the rooms is $24^{\circ} \mathrm{C}$ and the relative humidity is maintained at $40 \%$. There is a $12: 12 \mathrm{~h}$ light-dark regime with lights being turned on at 07:00. All birds are provided with a mixed seed diet (Life Care, Total Pet Care, Aalestrup, Denmark) and drinking water ad libitum. Finches at the age of 0.2 years (termed 'young'), 2.5 years (termed 'mid-age') and 5.1 years (termed 'old') were used in the present study. Zebra finches can live up to 5-6 years in the wild (Zann 1996). Thus, our captive colony is well representative of the entire lifespan of the species. Each age group consisted of 10 
females and 10 males which were chosen randomly from larger groups of birds of the same age. Mean age of young birds at blood sampling was $0.22 \pm 0.009$ years (females $0.22 \pm 0.015$ years, males $0.21 \pm 0.013$ years, $t$ test: $t=$ $-0.594, P=0.560$ ), mid-aged birds $2.52 \pm 0.017$ years (females $2.49 \pm 0.023$ years, males $2.53 \pm 0.025$ years, $t$ test: $t=1.032, P=0.316)$ and old birds $5.15 \pm$ 0.025 years (females $5.17 \pm 0.037$ years, males $5.12 \pm$ 0.034 years, $t$ test: $t=-1.016, P=0.323$ ). None of the birds had been breeding before, or during, the time of study.

During May-June 2008, blood samples (approx. $100 \mu \mathrm{l}$ ) were obtained from the brachial vein. Blood was collected within $3 \mathrm{~min}$ after entering the room to exclude the confounding effects of the stress hormone (corticosterone) on immune parameters (Matson et al. 2006b). The blood was subsequently centrifuged and plasma was stored at $-20^{\circ} \mathrm{C}$ until analysis of innate and humoral immunity. Assessment of cellular immunity by the injection of PHA was performed 14 days after blood sampling (see details below). Body mass and tarsus length were measured at each capture. Body condition index (BCI) was calculated separately for the two sexes as the standardized residuals from a linear regression with body mass as the dependent variable and tarsus length as the independent variable at both the time of blood sampling, as well as at the time of PHA injection.

\section{Cellular immune function: the PHA skin test}

Cell-mediated immunity (CMI) was assessed by quantifying the response to PHA injection (Goto et al. 1978; Tella et al. 2008). There has been some controversy on the PHA response being a reliable measure of the T cell mediated immune system given the complex nature of the response as it involves innate components (heterophils, monocytes and basophils; Martin et al. 2006). However, the response has been shown to reflect a reliable activation of the cellular immune system, as it is proceeded by a change in circulating $\mathrm{T}$ lymphocyte subsets and also to invoke a stronger secondary than primary response (Tella et al. 2008). Following the simplified protocol of Smits et al. (1999), the birds were injected subcutaneously in the right wing web (patagia) with $20 \mu \mathrm{g}$ of PHA-P (Sigma Chemical Co, L 9017; Smits et al. 1999) dissolved in $20 \mu \mathrm{l}$ of sterile phosphate buffered saline (PBS). The thickness of the patagia was measured five times (with an accuracy of $0.01 \mathrm{~mm}$ ) with a gauge micrometer (Mitutoyo) immediately prior to injection and $24 \pm 0.25 \mathrm{~h}$ after injection. The micrometer was modified with a detachable head that reduced the spindle's surface to $7 \mathrm{~mm}^{2}$.

Because the repeatability of the measurements was high (calculated according to Lessells and Boag (1987); pre-injection $R=0.80, \quad \mathrm{SE}=0.034, \quad P<0.001$, postinjection $R=0.95, \mathrm{SE}=0.009, P<0.001)$, mean change in thickness $(\mathrm{mm})$ of the wing (24-h post-injection thickness minus pre-injection thickness) was regarded as the measurement of the intensity of the CMI response and used as an index of the individual's cellular immunity (Goto et al. 1978). Handling time, as well as time of injection was recorded and controlled for since these parameters have been shown to affect the PHA response (Martinez-Padilla 2006; Berzins et al. 2008). Handling time was defined as time elapsed from entering the aviary to the release of the bird.

Humoral immune function: total immunoglobulin Y levels

To assess acquired humoral immunity, a sensitive enzymelinked immunoabsorbent assay (ELISA) was performed. By the use of commercial anti-chicken antibodies (Martinez et al. 2003), the total amount of immunoglobulin $Y$ was determined in the plasma of the zebra finches. To calculate the linear range of the sigmoid curve for the zebra finch plasma, ELISA plates were first coated with serial plasma dilutions $(100 \mu \mathrm{l})$ in carbonate-bicarbonate buffer $(0.1 \mathrm{M}$, $\mathrm{pH}$ 9.6) and incubated overnight at $4^{\circ} \mathrm{C}$. The dilution closest to the centre of its linear range was selected and used in the trials. 96-well ELISA plates were then coated with $100 \mu$ of diluted plasma samples ( 2 samples per bird diluted to $1 / 8,000$ in carbonate-bicarbonate buffer) and incubated first for $1 \mathrm{~h}$ at $37^{\circ} \mathrm{C}$ and then overnight at $4^{\circ} \mathrm{C}$. Next, the plates were washed with a $200 \mu \mathrm{l}$ solution of phosphate buffer saline and Tween (PBS-Tween), before $100 \mu \mathrm{l}$ of a solution of $5 \%$ powdered milk in PBS-Tween was added. After a second incubation at $37^{\circ} \mathrm{C}$ for $1 \mathrm{~h}$, the plates were washed with PBS-Tween and $100 \mu \mathrm{l}$ of polyclonal rabbit anti-chicken $\operatorname{IgG}$ conjugated with peroxidase (Sigma A-9046) at 1:250 (v/v) was added. Following 2-h incubation at $37^{\circ} \mathrm{C}$, the plates were washed with PBSTween three times. Finally, $100 \mu \mathrm{l}$ of revealing solution [peroxide diluted $1: 1,000$ in ABTS (2,2'-azino-bis(3-ethylbenzthiazoline-6-sulphonic acid))] was added, and the plates incubated for $1 \mathrm{~h}$ at $37^{\circ} \mathrm{C}$. The final absorbance was measured at $405 \mathrm{~nm}$ using a Victor $^{3}$ multilabel plate reader (PerkinElmer, Turku, Finland) and subsequently used to assess total plasma IgY levels.

Innate immune function: bactericidal competence

The bacteria-killing ability of plasma from the zebra finches against Escherichia coli was measured. This test is considered to assess constitutive, innate immunity (Tieleman et al. 2005; Matson et al. 2006b). Following an experimental protocol derived from Matson et al. (2006b) 
plasma $(20 \mu \mathrm{l})$ was diluted with $180 \mu \mathrm{l}$ solution consisting of $\mathrm{CO}_{2}$-independent media (\#18045 Gibco-Invitrogen, UK), $4 \mathrm{mM}$ L-glutamine and 5\% heat-inactivated fetal calf serum in $1.5 \mathrm{~mL}$ sterile capped tubes. To each diluted plasma sample, $20 \mu \mathrm{l}$ working solution of $E$. coli bacteria culture (approximately 200 bacteria) was added before the samples were vortexed and incubated for $30 \mathrm{~min}$ at $41^{\circ} \mathrm{C}$. The E. coli (ATCC \#8739) culture was prepared from lyophilized pellets following the manufacturer's instructions (Epower Microorganisms no. 04837E7, MicroBioLogics, St. Cloud, MN). After incubation, the samples were vortexed, and subsamples of $75 \mu$ were spread evenly onto agar plates in duplicates. After a drying period ( $\sim 20 \mathrm{~min})$, the agar plates were covered, inverted and incubated at $34^{\circ} \mathrm{C}$ overnight. The number of colonies was counted the next day. The average number of the two plates was compared with the number of colonies on control plates obtained by diluting bacteria in media alone. If the number of the individual's agar plates was smaller than that of the control plates, the individual was considered to exhibit bacteria-killing ability. All bacterial stages that required a sterile working environment were carried out in a laminar flow hood (Holten LaminAir).

\section{Statistical analyses}

All statistical analyses were performed using SPSS 15.0 (SPSS Inc. 2006). Variables were checked for normality (Kolmogorov-Smirnov test, $P>0.05$ ) and transformed when necessary (log-transformation for $\operatorname{IgY}$ levels). Means are given with standard errors. We used general linear models (GLM) to examine the effect of age and sex on both cellular and humoral acquired immunity. Because there are numerous other factors that can affect immune responses (see Norris and Evans (2000) for a review), we statistically controlled for potential confounding factors such as time of day for PHA injection, handling time and body condition to assess the unique role of age in immunity variation and possible immunosenescence patterns. In addition, we investigated all possible interactions between the factors, but since preliminary tests showed that none reached statistical significance, only the sex $\times$ age interaction are shown in the results. The final GLMs were obtained with non-significant variables stepwise being excluded one by one. Variables with $P<0.1$ were kept in the final models. Innate immune function was analyzed only in regard to individuals exhibiting plasma bacteria-killing ability or not by $\chi^{2}$ test for independence due to low sample size. Sample sizes vary among immune function analyses because we were not always able to perform all assays for all individuals due to lack of available plasma or unsuccessful injections of PHA.

\section{Results}

Cellular immune function

Cell-mediated immunity quantified through PHA response did not vary with handling time or time of injection $(P>0.75)$, both parameters being experimentally controlled for and confined to narrow intervals of 142-326 s and 08:27-10:59 a.m. respectively. Neither did we find any effect of body condition on cellular immunity (Table 1). However, the PHA response did vary with both age and sex (Table 1; Fig. 1). Post hoc comparisons using the Tukey test showed that mean CMI for the mid-age group $(0.97 \pm 0.038 \mathrm{~mm})$ was significantly higher than that of the old group $(0.75 \pm 0.039 \mathrm{~mm} ; P<0.001)$. The mean CMI of the young group $(0.86 \pm 0.039 \mathrm{~mm})$ did not differ significantly from neither the mid-age group $(P=0.137)$ nor the old group $(P=0.096)$. There was a statistically significant difference between males and females, with males having stronger cellular immune function than females (Table 1; mean value for males being $0.93 \pm 0.032 \mathrm{~mm}$, and for females $0.79 \pm 0.032 \mathrm{~mm}$ ) independently of the age group.

\section{Humoral immune function}

Total plasma levels of IgY did not significantly vary with body condition, nor was there a significant effect of the interaction between age and sex (Table 2). Females tended to have higher IgY levels than males (females $0.332 \pm 0.023$ absorbance units, males $0.285 \pm 0.023$ absorbance units, Fig. 2), however, the difference was not statistically significant $(P=0.094$, Table 2$)$. Tukey post hoc tests showed that IgY levels observed in the young group (0.199 \pm 0.028 absorbance units) were significantly lower than the levels in both the mid-age $(0.324 \pm 0.029$ absorbance units) and the old group $(0.403 \pm 0.027$

Table 1 Summary of a GLM explaining variation in cell-mediated immunity quantified through PHA response $(\mathrm{mm})$ of zebra finches in relation to age, sex, body condition, time of injection and handling time

\begin{tabular}{llllll}
\hline Final model & $d f$ & $F$ & $P$ & $r^{2}$ & Estimate \pm SE \\
\hline Age & 2,54 & 8.077 & 0.001 & 0.23 & \\
Sex & 1,54 & 9.704 & 0.003 & 0.15 & $0.141 \pm 0.045$ \\
Rejected variables & & & & & \\
$\quad$ Body condition & 1,53 & 0.345 & 0.559 & 0.01 & $-0.015 \pm 0.025$ \\
Age $\times$ sex & 2,51 & 0.563 & 0.573 & 0.02 & \\
Handling time & 1,50 & 0.100 & 0.753 & 0.00 & $0.000 \pm 0.001$ \\
Time of injection & 1,49 & 0.067 & 0.797 & 0.00 & $0.000 \pm 0.001$ \\
\hline
\end{tabular}

$n=58$. Total $r^{2}$ for final model $=0.38$; the estimate for sex shows males compared to females 


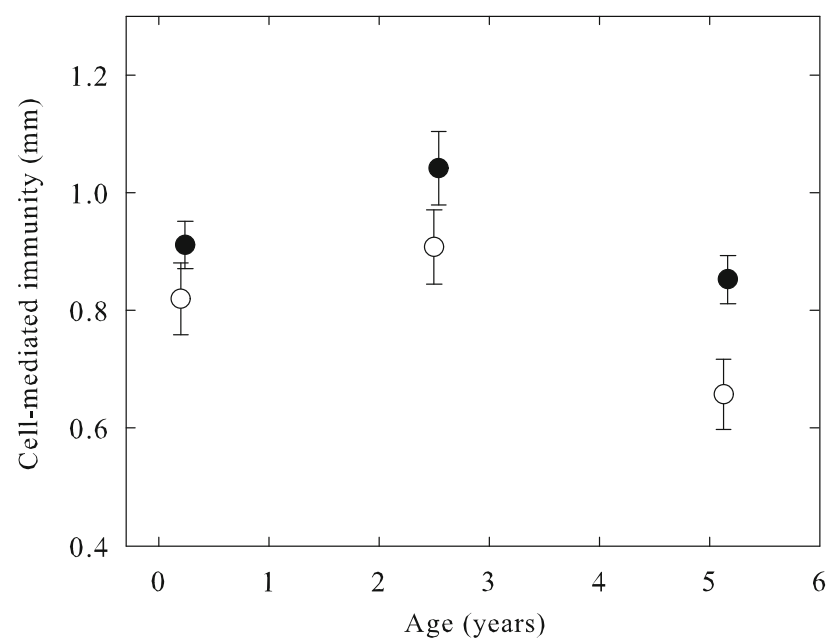

Fig. 1 Cell-mediated immunity ( $\mathrm{mm}$ ) of young, mid-aged and old zebra finches (mean $\pm \mathrm{SE}$ ). Open symbols show females, while closed symbols show males (see text for statistics)

absorbance units, $P<0.001$ in both cases). The old group and the mid-age group did, however, not differ significantly in $\operatorname{IgY}$ levels $(P=0.144)$. Nevertheless, the significant effect of age $(P<0.001$, Table 2$)$ points to an overall increase in the total plasma IgY levels with age in zebra finches (Fig. 2).

Innate immune function

Among the young finches, seven females and five males (60\% of the individuals) exhibited plasma bacteria-killing ability (Fig. 3). There were six females and two males $(40 \%)$ in the mid-age group, and only three females and no males $(15 \%)$ in the old age group displaying this ability (Fig. 3). Although the number of females showing plasma bacteria-killing ability did not differ significantly between the age groups $\left[\chi^{2}\right.$ test for independence: $\chi^{2}(2, n=$ $30)=3.482 . P=0.175]$, the number of males that did decreased significantly with age $\left(\chi^{2}\right.$ test for independence: $\left.\chi^{2} \quad(2, n=30)=7.081 . \quad P=0.029\right)$. Owing to the

Table 2 Summary of a GLM explaining variation in humoral immunity represented by immunoglobulin Y levels (absorbance units) in relation to age, sex and body condition

\begin{tabular}{llrrrr}
\hline Final model & $d f$ & \multicolumn{1}{l}{$F$} & \multicolumn{1}{l}{$P$} & $r^{2}$ & Estimate \pm SE \\
\hline Age & 2,53 & 21.428 & $<0.001$ & 0.45 & \\
Sex & 1,53 & 2.912 & 0.094 & 0.05 & $-0.065 \pm 0.038$ \\
Rejected variables & & & & & \\
Body condition & 1,52 & 0.985 & 0.326 & 0.02 & $0.022 \pm 0.022$ \\
Age $\times$ sex & 2,50 & 0.027 & 0.973 & 0.00 & \\
\hline
\end{tabular}

$n=57$. Total $r^{2}$ for final model $=0.50$; the estimate for sex shows males compared with females

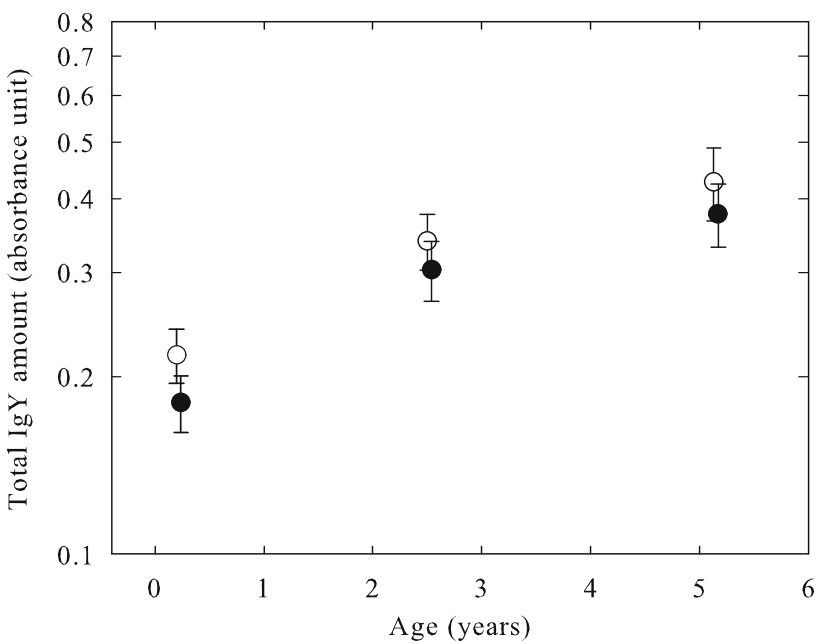

Fig. 2 Humoral immunity represented by the total immunoglobulin amount (absorbance units) in young, mid-aged and old zebra finches (mean $\pm \mathrm{SE}$ ). Open symbols show females, while closed symbols show males (see text for statistics)

consecutive low sample size, further analysis on the strength of bactericidal competence was not carried out.

\section{Discussion}

We found that the cellular immune function, quantified through a PHA response, did change with age (Table 1). Even though only old birds differed significantly from midaged birds, the CMI response seemed to follow an inverse U-shaped pattern with increasing age (Fig. 1). Our results indicate a trend for both young and old zebra finches of having weaker CMI responses than mid-aged individuals which is in accordance with the previous studies on birds (Lozano and Lank 2003; Haussmann et al. 2005; Lavoie

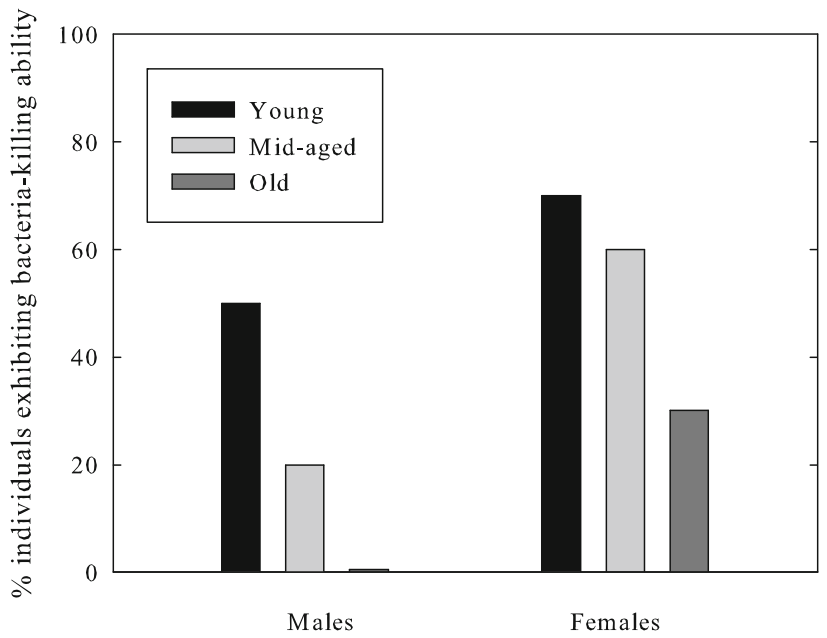

Fig. 3 Percentage of male and female individuals showing plasma E. coli-killing ability in young, mid-aged and old zebra finches 
et al. 2007; Palacios et al. 2007). However, contrary to previous studies, our study is, to our knowledge, the first to show a sex-specific difference in cellular immune function in each age group. In addition, it is the first study to show that cellular immunosenescence is displayed in both sexes of zebra finches.

Low immune responses in young individuals is a common finding among birds (Apanius 1998), and is typically attributed to developmental constraints and/or trade-offs between energy and/or resource demanding activities (Lozano and Lank 2003). In order to quickly reach a reproductive state, immature individuals are expected to prioritize sexual maturation over immune function compared to adult individuals (Roff 1992). Accordingly, the low CMI responses observed in the young cohort may reflect this prioritizing and hence the immaturity of their immune system since the majority had not reached their sexual maturity age of 90 days (Zann 1996). The low CMI responses found in the old finches might also be explained by life-history theory, which states that there is an optimal trade-off strategy between investment in self-maintenance and reproduction in relation to maximizing fitness (Stearns 1992). Since increasing age leads to a lower lifespan expectation, resources should be skewed in favor of reproduction over self-maintenance (i.e. 'terminal investment'; Clutton-Brock 1984). Thus, old individuals should then invest relatively less in immune function compared to younger individuals (Cichon 2001).

Since cellular immunity was significantly affected by sex, with female finches mounting lower CMI responses than males, independently of age (Table 1; Fig. 1), it may be indicative of a lower investment in cellular immune function by females compared with males and such a sexspecific difference in cellular immunity is in contrast to other studies on the same species in which no sex difference in the CMI response was reported (e.g. Verhulst et al. 2005; Roberts et al. 2007; Tobler et al. 2010).

Unlike the cellular immunity, the acquired humoral immunity did not show any significant sex-specific differences. Even though females tended to show higher $\operatorname{IgY}$ levels than males (Fig. 2; Table 2), only age explained the variation in IgY levels (Table 2). Although only IgY levels observed in the young group differed significantly from the two other groups, our results suggest significant increased IgY levels with age (Fig. 2). With the exception of Apanius and Nisbet (2003), previous studies on immunosenescence in birds have assessed humoral immunity using other techniques than that used in the present study, making the different immunological measures and the result, including ours, hard and/or impossible to compare (Viney et al. 2005). In mammals, elevated levels of IgG (analogous to avian $\mathrm{IgY}$ ) is a common feature in old individuals caused by intrinsic $\mathrm{B}$ cell defects, e.g. benign monoclonal gammopathies, and failing $\mathrm{T}$ cell regulation control on $\mathrm{B}$ cell function (Malaguarnera et al. 2001; Grubeck-Loebenstein and Wick 2002). It is tempting to speculate that if such malfunction of the immune system (immunosenescence) is also present in birds, it could explain the agerelated increase in IgY levels found in the present study.

Whether high levels of circulating IgY actually reflect a high immunocompetence is also debatable. Because $\operatorname{IgY}$ is the most important antibody involved in avian humoral response (Davison et al. 2008), a high concentration could on one hand reflect a strong humoral immune system (Johnsen and Zuk 1999; Saino et al. 2001). On the other hand, it could also be the result of an ongoing immune response to a current infection (Norris and Evans 2000). In the present study, our captive birds have been kept at stable indoor conditions and hence the extent to exposure of pathogens are presumed to be low, thus lowering the probability of an increasing agerelated infection rate. Still, since high IgY concentrations can be regarded as both symptomatic of infection and/or disease and as an indicator of strong immunocompetence, our results should be interpreted with caution. Challenging assays of humoral immunity might consequently be more informative of the immunocompetence of birds (Norris and Evans 2000). However, challenging both acquired immune components simultaneously might also raise practical problems and produce controversial results. Because a trade-off between the components may occur, and because of the close interaction and dependency between the acquired immune components (Goldsby et al. 2003), concurrent challenge may influence the effectiveness of the respective responses (Norris and Evans 2000).

The analysis of the innate immune function showed that the number of male zebra finches exhibiting plasma killing ability decreased significantly with age. The same trend was found in females, although it was not statistically significant. Even though the low sample size could be argued not to allow us enough statistical power to draw any realistic conclusions about these differences, the decrease in the number of individuals exhibiting bacterial-killing ability with age, although to be regarded as preliminary results only, is nonetheless very interesting. To our knowledge, only Tieleman et al. (2010) have used the same methodology to assess innate immunity in relation to age in birds and their results are contradicting ours. Indeed, they reported that microbicidal capacity against E. coli increased with age (1-7 years) in European stonechats (Saxicola torquata rubicola). On the other hand, Palacios et al. (2007) assessed the innate immunity in relation to age in female tree swallows measuring the levels of circulating natural antibodies (NAbs) and complement, and they did not find any age-related changes. Using the same assay, Møller and Haussy (2007) showed that old barn swallows had reduced levels of NAbs, but not of complement- 
mediated cell lysis. Even though some other immunological studies have included age as a parameter (e.g. Buehler et al. 2009; De Coster et al. 2010), studies evaluating the innate immunity in an immunosenescence context and comprising the entire lifespan of a species are lacking. Hence, there is still a strong need for more studies on innate immunity to fully understand its variation with age.

Studies on both humans and rodents have shown that the acquired immune system declines and deteriorates more profoundly with age than the innate immune system, and also that $\mathrm{T}$ cells are more affected than B cells (Franceschi et al. 2000; Pawelec et al. 2002; Son et al. 2003). We are not able to draw any similar conclusions if this also applies to our birds because of the insufficient result on innate immunity. However, our study does report a decline in the acquired immune system in both male and female zebra finches, if we presume that the increase in IgY levels reflect a malfunction of the humoral immune system. Because the altered immunoglobulin production with age has been proposed to likely be a consequence of failing $\mathrm{T}$ cell function (Malaguarnera et al. 2001), it makes it difficult to disentangle the complex and intricate relationship between the different arms of the acquired immune system, and hence elucidate which of the components are most affected by immunosenescence.

Whether the immunosenescence found in our captive zebra finch population is applicable to free-living zebra finches remains to be determined. Nevertheless, both age and sex have been demonstrated to significantly affect immune function and these factors must be controlled for in future studies. Finally, knowledge of the basic ageing mechanisms using birds as a model organism has great value for a better understanding of the diseases arising with ageing. In addition, in line with concerns about the ongoing global warming with possible redistribution of parasites and outbreaks of new viruses, more emphasis should be placed on avian immune-ecology.

Acknowledgments We would like to thank Odd Arne Indset and Bjørn Simensen for taking care of our birds. The project was supported by a PhD-Grant from the Norwegian University of Science and Technology. We are grateful for the two anonymous referees for constructive comments on the manuscript.

Open Access This article is distributed under the terms of the Creative Commons Attribution Noncommercial License which permits any noncommercial use, distribution, and reproduction in any medium, provided the original author(s) and source are credited.

\section{References}

Apanius V (1998) Ontogeny of immune function. In: Starck JM, Ricklefs RE (eds) Avian growth and development: evolution within the altricial-precocial spectrum. Oxford University Press, New York, pp 203-221

Apanius V, Nisbet ICT (2003) Serum immunoglobulin G levels in very old common terns Sterna hirundo. Exp Gerontol 38:761-764

Berzins LL, Tilman-Schindel E, Burness G (2008) Sex-specific effects of handling time on an index of immune activity in zebra finches. Physiol Biochem Zool 81:383-387

Blasco MA (2002) Immunosenescence phenotypes in the telomerase knockout mouse. Springer Semin Immunopathol 24:75-85

Braude S, Tang-Martinez Z, Taylor GT (1999) Stress, testosterone, and the immunoredistibution hypothesis. Behav Ecol 10:333-350

Buehler DM, Tieleman BI, Piersma T (2009) Age and environment affect constitutive immune function in red knots (Calidris canutus). J Ornithol 150:815-825

Cichon M (2001) Diversity of age-specific reproductive rates may result from ageing and optimal resource allocation. J Evol Biol 14:180-185

Cichon M, Sendecka J, Gustafsson L (2003) Age-related decline in humoral immune function in collared flycatchers. J Evol Biol 16:1205-1210

Clutton-Brock TH (1984) Reproductive effort and terminal investment in iteroparous animals. Am Nat 123:212-229

Davison F, Magor KE, Kaspers B (2008) Structure and evolution of avian immunoglobulins. In: Davison F, Kaspers B, Schat KA (eds) Avian immunology. Academic Press, London, pp 107-127

De Coster G, De Neve L, Martin-Galvez D, Therry L, Lens L (2010) Variation in innate immunity in relation to ectoparasite load, age and season: a field experiment in great tits (Parus major). J Exp Biol 213:3012-3018

Effros RB (2003) Genetic alterations in the ageing immune system: impact on infection and cancer. Mech Ageing Dev 124:71-77

Folstad I, Karter AJ (1992) Parasites, bright males, and the immunocompetence handicap. Am Nat 139:603-622

Franceschi C, Bonafe M, Valensin S (2000) Human immunosenescence: the prevailing of innate immunity, the failing of clonotypic immunity, and the filling of immunological space. Vaccine 18:1717-1720

Goldsby RA, Kindt TJ, Osborne BA, Kuby J (2003) Immunology, 5th edn. W. H. Freeman and Company, New York

Gomez CR, Nomellini V, Faunce DE, Kovacs EJ (2008) Innate immunity and aging. Exp Gerontol 43:718-728

Goto N, Kodama H, Okada K, Fujimoto Y (1978) Suppression of phytohemagglutinin skin response in thymectomized chickens. Poultry Sci 57:246-250

Grubeck-Loebenstein B, Wick G (2002) The aging of the immune system. Adv Immunol 80:43-284

Haussmann MF, Winkler DW, Huntington CE, Vleck D, Sanneman CE, Hanley D, Vleck CM (2005) Cell-mediated immunosenescence in birds. Oecologia 145:270-275

Holmes D, Martin K (2009) A bird's-eye view of aging: what's in it for ornithologists? Auk 126:1-23

Holmes DJ, Ottinger MA (2003) Birds as long-lived animal models for the study of aging. Exp Gerontol 38:1365-1375

Johnsen TS, Zuk M (1999) Parasites and tradeoffs in the immune response of female red jungle fowl. Oikos 86:487-492

Lavoie ET, Sorrell EM, Perez DR, Ottinger MA (2007) Immunosenescence and age-related susceptibility to influenza virus in Japanese quail. Dev Comp Immunol 31:407-414

Lessells CM, Boag PT (1987) Unrepeatable repeatabilities: a common mistake. Auk 104:116-121

Lozano GA, Lank DB (2003) Seasonal trade-offs in cell-mediated immunosenescence in ruffs (Philomachus pugnax). Proc R Soc Lond B 270:1203-1208 
Malaguarnera L, Ferlito L, Imbesi RM, Gulizia GS, Di Mauro S, Maugeri D, Malaguarnera M, Messina A (2001) Immunosenescence: a review. Arch Gerontol Geriatr 32:1-14

Martin LB, Han P, Lewittes J, Kuhlman JR, Klasing KC, Wikelski M (2006) Phytohemagglutinin-induced skin swelling in birds: histological support for a classic immunoecological technique. Funct Ecol 20:290-299

Martinez J, Tomas G, Merino S, Arriero E, Moreno J (2003) Detection of serum immunoglobulins in wild birds by direct ELISA: a methodological study to validate the technique in different species using antichicken antibodies. Funct Ecol 17:700-706

Martinez-Padilla J (2006) Daytime variation in T-cell-mediated immunity of Eurasian kestrel Falco tinnunculus nestlings. J Avian Biol 37:419-424

Matson KD, Cohen AA, Klasing KC, Ricklefs RE, Scheuerlein A (2006a) No simple answers for ecological immunology: relationships among immune indices at the individual level break down at the species level in waterfowl. Proc R Soc Lond B 273:815-822

Matson KD, Tieleman BI, Klasing KC (2006b) Capture stress and the bactericidal competence of blood and plasma in five species of tropical birds. Physiol Biochem Zool 79:556-564

Miller RA (1996) The aging immune system: primer and prospectus. Science 273:70-74

Møller AP, Haussy C (2007) Fitness consequences of variation in natural antibodies and complement in the Barn Swallow Hirundo rustica. Funct Ecol 21:363-371

Monaghan P, Charmantier A, Nussey DH, Ricklefs RE (2008) The evolutionary ecology of senescence. Funct Ecol 22:371-378

Norris K, Evans MR (2000) Ecological immunology: life history trade-offs and immune defense in birds. Behav Ecol 11:19-26

Palacios MG, Cunnick JE, Winkler DW, Vleck CM (2007) Immunosenescence in some but not all immune components in a freeliving vertebrate, the tree swallow. Proc R Soc Lond B 274:951-957

Pawelec G, Barnett Y, Forsey R, Frasca D, Globerson A, McLeod J, Caruso C, Franceschi C, Fulop T, Gupta S, Mariani E, Mocchegiani E, Solana R (2002) T cells and aging. January 2002 update. Front Biosci 7:1056-1183

Roberts ML, Buchanan KL, Hasselquist D, Evans MR (2007) Effects of testosterone and corticosterone on immunocompetence in the zebra finch. Horm Behav 51:126-134
Roff DA (1992) The evolution of life histories: theory and analysis. Chapman \& Hall, New York

Saino N, Incagli M, Martinelli R, Ambrosini R, Møller AP (2001) Immunity, growth and begging behaviour of nestling barn swallows Hirundo rustica in relation to hatching order. J Avian Biol 32:263-270

Saino N, Ferrari RP, Romano M, Rubolini D, Møller AP (2003) Humoral immune response in relation to senescence, sex and sexual ornamentation in the barn swallow (Hirundo rustica). J Evol Biol 16:1127-1134

Smits JE, Bortolotti GR, Tella JL (1999) Simplifying the phytohaemagglutinin skin-testing technique in studies of avian immunocompetence. Funct Ecol 13:567-572

Son NH, Joyce B, Hieatt A, Chrest FJ, Yanovski J, Weng NP (2003) Stable telomere length and telomerase expression from naive to memory B-lymphocyte differentiation. Mech Ageing Dev $124: 427-432$

Stearns SC (1992) The evolution of life histories. Oxford University Press, Oxford

Tella JL, Lemus JA, Carrete M, Blanco G (2008) The PHA test reflects acquired T-cell mediated immunocompetence in birds. PLoS ONE 3:e3295

Tieleman BI, Williams JB, Ricklefs RE, Klasing KC (2005) Constitutive innate immunity is a component of the pace-of-life syndrome in tropical birds. Proc R Soc Lond B 272:1715-1720

Tieleman BI, Croese E, Helm B, Versteegh MA (2010) Repeatability and individual correlates of microbicidal capacity of bird blood. Comp Biochem Physiol A 156:537-540

Tobler M, Hasselquist D, Smith HG, Sandell MI (2010) Short- and long-term consequences of prenatal testosterone for immune function: an experimental study in the zebra finch. Behav Ecol Sociobiol 64:717-727

Trivers RL (1972) Parental investment and sexual selection. In: Campbell B (ed) Sexual selection and the descent of man, 1871-1971. Aldine Publishing, London, pp 136-179

Verhulst S, Riedstra B, Wiersma P (2005) Brood size and immunity costs in zebra finches Taeniopygia guttata. J Avian Biol $36: 22-30$

Viney ME, Riley EM, Buchanan KL (2005) Optimal immune responses: immunocompetence revisited. Trends Ecol Evol 20:665-669

Zann RA (1996) The zebra finch: a synthesis of field and laboratory studies. Oxford University Press, Oxford 